\begin{tabular}{|c|c|}
\hline Title & $\begin{array}{l}\text { A Glove-Box- and Schlenk-Line-Free Protocol for Solid-State C-N Cross Coupling Reactions U sing } \\
\text { Mechanochemistry }\end{array}$ \\
\hline Author(s) & Kubota, Koji; Takahashi, Rikuro; U esugi, Minami; Ito, Haj ime \\
\hline Citation & $\begin{array}{l}\text { Sustainable Chemistry \& Engineering, 8(44), } 16577-16582 \\
\text { https://doi.org/10.1021/acssuschemeng.0c05834 }\end{array}$ \\
\hline Issue Date & 2020-11-09 \\
\hline Doc URL & http:/hdl .handle.net/2115/83287 \\
\hline Rights & $\begin{array}{l}\text { This document is the A ccepted Manuscript version of a Published Work that appeared in final form in [A CS sustainable } \\
\text { chemistry \& engineering], copyright c A merican Chemical Society after peer review and technical editing by the } \\
\text { publisher. To access the final edited and published work see [https://pubs.acs.org/doi/10.1021/acssuschemeng.0c05834]. }\end{array}$ \\
\hline Type & article (author version) \\
\hline File Information & manuscript.pdf \\
\hline
\end{tabular}

Instructions for use 


\title{
A Glove-box- and Schlenk-line-free Protocol for Solid-state C-N Cross-coupling Reactions Using Mechanochemistry
}

\author{
Koji Kubota, ${ }^{*}, \ddagger$ Rikuro Takahashi, ${ }^{\dagger}$ Minami Uesugi, ${ }^{\dagger}$ and Hajime Ito*†, \\ †Division of Applied Chemistry, Graduate School of Engineering, Hokkaido University, Kita 13 Nishi 8, Sapporo, Hok- \\ kaido 060-8628, Japan. \\ ‡Institute for Chemical Reaction Design and Discovery (WPI-ICReDD), Hokkaido University, Kita 21 Nishi 10, Sapporo, \\ Hokkaido 060-8628, Japan.
}

\begin{abstract}
Carbon-nitrogen (C-N) bond-forming cross-coupling reactions catalyzed by palladium-based catalysts, the socalled Buchwald-Hartwig aminations, have been widely employed for the synthesis of pharmaceuticals and aryl-amine-based organic materials in academic and industrial settings. However, in solution, these reactions usually require glove-box and Schlenk-line techniques, which greatly reduces their practical utility. Here, we report the development of operationally simple mechanochemical C-N cross-coupling reactions in the solid-state. Intensive investigations of various ball milling parameters revealed that the air-stable ligand tri(1-adamantyl)phosphine can be used to achieve solid-state coupling reactions between aryl halides and diarylamines with high efficiency. Notably, all experimental operations of the developed protocol can be carried out in air, thus providing a more convenient, industrially attractive, and sustainable alternative to conventional solution-based palladium-catalyzed $\mathrm{C}-\mathrm{N}$ coupling reactions.
\end{abstract}

\section{KEYWORDS: Mechanochemistry, Ball mill, Cross-cou- pling, Solid-state reactions, Triarylamine}

\section{INTRODUCTION}

The development of carbon-nitrogen $(\mathrm{C}-\mathrm{N})$ bond-forming coupling reactions catalyzed by transition-metals is of great importance in the synthesis of nitrogen-containing pharmaceuticals and organic electro and optical materials. ${ }^{1-3}$ Palladium-based catalysts have been widely used for the cross-coupling of aryl halides with amine nucleophiles, the so-called Buchwald-Hartwig aminations. ${ }^{1-9}$ However, these reactions usually necessitate synthetic techniques that involve glove boxes and/or high-vacuum Schlenk lines, which are costly and require special training. ${ }^{10,11}$ Additionally, significant amounts of dry and degassed organic solvents are used in these reactions. Thus, the development of operationally simple, solvent-free palladium-catalyzed $\mathrm{C}-\mathrm{N}$ coupling reactions would greatly improve the practicality of the desired aryl amine derivatives.

In this context, the use of ball-milling techniques for solvent-free palladium-catalyzed $\mathrm{C}-\mathrm{N}$ bond-forming coupling reactions that can be carried out in air has attracted attention. ${ }^{12-41}$ In 2018, Su and co-workers reported the first example of the use of ball milling to carry out solvent-free mechanochemical $\mathrm{C}-\mathrm{N}$ coupling reactions in air in the presence of $\mathrm{Pd}(\mathrm{OAc})_{2} / \mathrm{XPhos}$ as a catalyst. ${ }^{31}$ Almost simultaneously, Browne and co-workers developed robust mechanochemical C-N coupling reactions in air using PdPEPPSI-iPENT as the catalyst. ${ }^{32}$ Although these pioneering studies are remarkable, they are mainly focused on liquid substrates that serve as both reactants and the reaction solvent. As most aryl-amine-based organic materials exhibit extended polyaromatic structures and are prepared from solid starting materials, ${ }^{42-44}$ the development of mechanochemical cross-coupling reactions of solid aryl halides with solid amine nucleophiles in air would be highly desirable.

We have previously reported the first general solidstate palladium-catalyzed $\mathrm{C}-\mathrm{N}$ cross-coupling reactions using mechanochemistry (Scheme 1A). ${ }^{33}$ The key to achieving this mechanochemical transformation was the addition of small amounts of olefins such as 1,5-cyclooctadiene (1,5-cod). These additives can act as dispersants and stabilizers to facilitate the $\mathrm{C}-\mathrm{N}$ cross-coupling in the solidstate reaction environment. ${ }^{28}$ However, this procedure still requires glove-box techniques, as highly air-sensitive tri-tert-butylphosphine $\left(t-\mathrm{Bu}_{3} \mathrm{P}\right)$ is used as the ligand..$^{45}$ This restriction greatly reduces the practical utility of the mechanochemical protocol.

Herein, we report a comprehensive investigation of various ball-milling parameters, which revealed that the airstable tri(1-adamantyl)phosphine $\left(\operatorname{Ad}_{3} \mathrm{P}\right)^{46}$ can be used successfully in mechanochemical solid-state $\mathrm{C}-\mathrm{N}$ coupling reactions under ambient conditions (Scheme 1A). Compared to the previous mechanochemical reaction using $t$ $\mathrm{Bu}_{3} \mathrm{P}$ as the ligand, ${ }^{45}$ the newly developed system shows comparable substrate generality. But more importantly, all experimental operations of the modified protocol can be carried out under ambient conditions, i.e., the chemicals, reagents, and catalysts can be added to the milling jar in air (Scheme 1B). Thus, this operationally simple protocol provides a more convenient, industrially attractive, and sustainable alternative to conventional solutionbased palladium-catalyzed $\mathrm{C}-\mathrm{N}$ coupling reactions. 
Mechanistic studies to elucidate the effect of varying the mechanochemical conditions on this solid-state $\mathrm{C}-\mathrm{N}$ cross-coupling reaction are also described.

Scheme 1. Glove-box- and Schlenk-line-free Protocol for Solid-State $\mathrm{C}-\mathrm{N}$ Cross-Coupling Reactions.

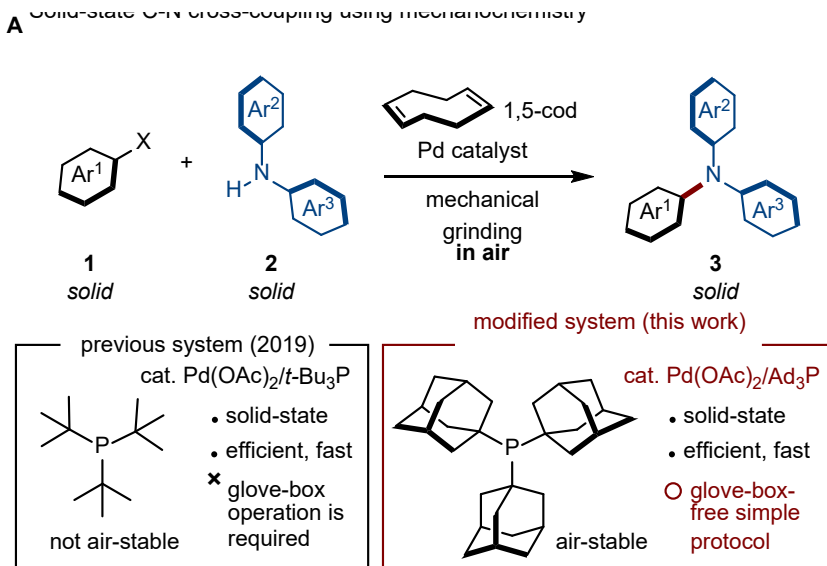

B Reaction set-up $^{\text {Ren }}$
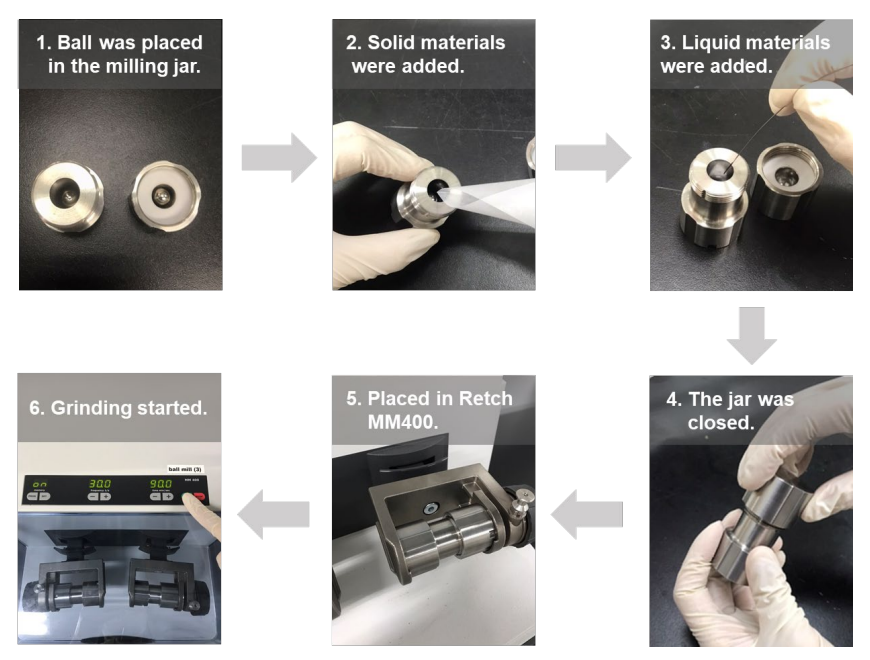

\section{RESULTS AND DISCUSSION}

In light of our previous studies, we have been interested in identifying monodentate ligands that exhibit catalytic properties similar to or better than those of $t$ - $\mathrm{Bu}_{3} \mathrm{P}$. To this end, we began our investigation by exploring the ligand effect in the solid-state mechanochemical C-N cross-coupling in the presence of 1,5-cod as a liquid-assisted-grinding (LAG) additive. ${ }^{33}$ Reactions were conducted in a stainless-steel milling jar (SUS420J2, $1.5 \mathrm{~mL}$ ) with one stainless-steel ball (SUS420J2, diameter: $5 \mathrm{~mm}$ ) using a Retsch MM400 mill at $30 \mathrm{~Hz}$. First, we conducted the mechanochemical palladium-catalyzed cross-coupling between a solid aryl bromide (1a) and diphenylamine (1) in the presence of tri-tert-butylphosphonium tetrafluoroborate $\left(t-\mathrm{Bu}_{3} \mathrm{P} \bullet \mathrm{HBF}_{4}\right)$, which is an air-stable precursor of $t-\mathrm{Bu}_{3} \mathrm{P}$. Although the use of $t-\mathrm{Bu}_{3} \mathrm{P}$ efficiently promoted the $\mathrm{C}-\mathrm{N}$ cross-coupling to form $3 \mathbf{a}$ in high yield (87\%) in our previous study, ${ }^{33}$ the reaction using $t-\mathrm{Bu}_{3} \mathrm{P} \bullet \mathrm{HBF}_{4}$ showed poor conversion and furnished $3 a$ in $14 \%$ yield under similar mechanochemical conditions (Table 1, entry 1). We then turned our attention to air-stable tri(1-adamantyl)phosphine (Ad3P), which was first synthesized by Carrow and co-workers. ${ }^{46-50}$ This ligand is sterically similar to
t-Bu3P but has been discovered to be more electron-donating. ${ }^{46-50}$ We thus reasoned that $\mathrm{Ad}_{3} \mathrm{P}$ might exhibit better catalytic properties than $t$ - $\mathrm{Bu}_{3} \mathrm{P}$ for the solid-state mechanochemical $\mathrm{C}-\mathrm{N}$ cross-coupling reactions. Pleasingly, the reaction using $\mathrm{Ad}_{3} \mathrm{P}$ proceeded efficiently under mechanochemical conditions to furnish 3a in good yield (72\%; Table 1, entry 2). In contrast, the use of Buchwald ligands, which are commonly employed in solution-based cross-coupling reactions, resulted in poor yields (Table 1, entries 3-6). Notably, the yield was very low when XPhos, which is the optimal ligand under the conditions reported by $\mathrm{Su},{ }^{31}$ was used $(8 \%$, Table 1 , entry 4$) .{ }^{51}$ No reaction was observed when we used Pd-PEPPSI-iPent, which is the optimal palladium-based catalyst under the conditions reported by Browne ${ }^{32}$ (Table 1, entry 7)..$^{51}$ We also confirmed that the use of 1,5-cod as a LAG additive and supporting ligands for the palladium-based catalyst are essential for this transformation (Table 1, entries 8 and 9).

Table 1. Ligand Effect on the Mechanochemical SolidState $\mathrm{C}-\mathrm{N}$ Cross-Coupling Reaction between $1 \mathrm{a}$ and $2 \mathrm{a}$ in Air. ${ }^{a}$

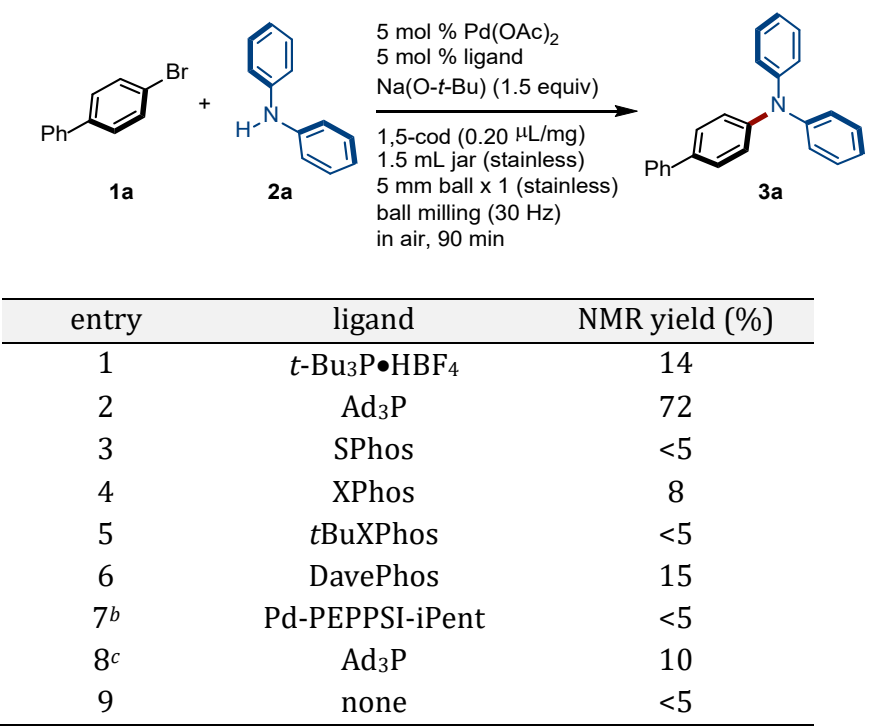

aConditions: 1a $(0.50 \mathrm{mmol}), 2$ a $(0.50 \mathrm{mmol}), \mathrm{Pd}(\mathrm{OAc})_{2}$ $(0.025 \mathrm{mmol})$, ligand $(0.025 \mathrm{mmol}), \mathrm{Na}(\mathrm{O}-\mathrm{t}-\mathrm{Bu})(0.75$ $\mathrm{mmol})$, and $1,5-\operatorname{cod}(0.20 \mu \mathrm{L} / \mathrm{mg})$ in a stainless-steel ballmilling jar $(1.5 \mathrm{~mL})$ with a stainless-steel ball (diameter: $5 \mathrm{~mm}$ ). Yields were determined by ${ }^{1} \mathrm{H}$ NMR analysis with $\mathrm{CH}_{2} \mathrm{Br}_{2}$ as an internal standard. ${ }^{b}$ Pd-PEPPSI-iPent (5 mol \%) was used instead of $\mathrm{Pd}(\mathrm{OAc})_{2} .{ }^{c}$ The reaction was carried out without 1,5-cod. 


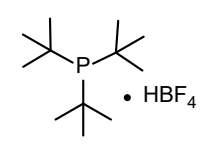

$t-\mathrm{Bu}_{3} \mathrm{P} \cdot \mathrm{HBF}_{4}$

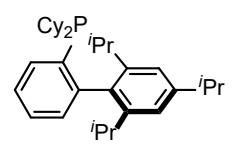

XPhos
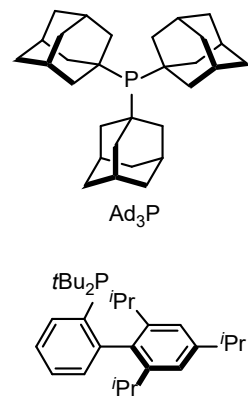

tBuXPhos
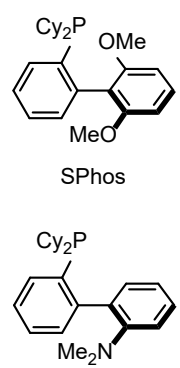

DavePhos
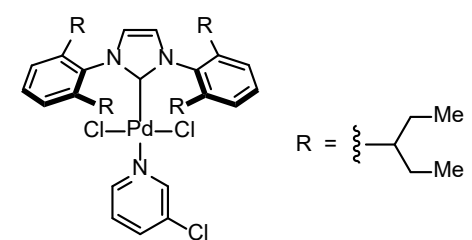

Pd-PEPPSI-iPent

To further improve the reactivity of the $\mathrm{Pd}(\mathrm{OAc})_{2} / \mathrm{Ad}_{3} \mathrm{P}$ system, the effect of the ball-milling conditions on the solid-state $\mathrm{C}-\mathrm{N}$ cross-coupling reaction was investigated (Table 2). For this purpose, the reaction between 1a and 2a was performed in a larger stainless-steel jar $(5.0 \mathrm{~mL})$ using one stainless-steel ball (diameter: $10 \mathrm{~mm}$ ) (Table 2, entry 2). Unfortunately, this resulted in a lower yield (51\%) than conducting the reaction in a $1.5 \mathrm{~mL}$ stainlesssteel milling jar using a 5-mm ball (Table 2, entry 1 ). The use of an agate or $\mathrm{ZrO}_{2}$ jar also significantly decreased the yield of 3a (16\% and 5\%, respectively; Table 1, entries 3 and 4). In our previous study on the development of a mechanochemical solid-state Suzuki-Miyaura cross-coupling reaction, ${ }^{28}$ the product yields have increased significantly with increasing mechanical impact, which suggested that strong mechanical stimulation facilitates uniform dispersion of the reactants, palladium-based catalysts, and bases in the solid-state reaction mixture. With this in mind, we investigated the effect of the number of balls (Table 1, entries 5 and 6). As anticipated, the yield of 3a improved dramatically when three balls (diameter: 10 $\mathrm{mm}$ ) were used (>99\%; Table 1, entry 6). Under these optimized conditions, the reaction using $t-\mathrm{Bu}_{3} \mathrm{P} \bullet \mathrm{HBF}_{4}$ provided 3a in good yield (67\%; Table 1, entry 7), albeit that the use of $\mathrm{Ad}_{3} \mathrm{P}$ affords the most satisfactory results.

Table 2. Investigation of the Effect of Varying the Mechanochemical Parameters. ${ }^{a}$

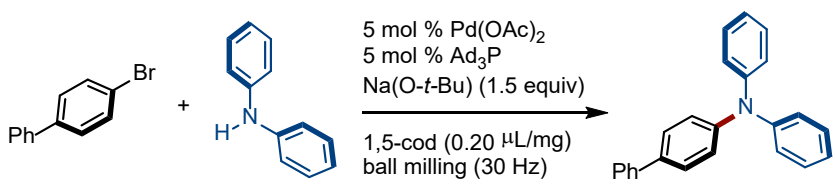

$1 \mathrm{a}$ $2 a$ in air, $90 \mathrm{~min}$ $3 a$

\begin{tabular}{cccccc}
\hline $\begin{array}{c}\text { en- } \\
\text { try }\end{array}$ & $\begin{array}{c}\text { jar/ball ma- } \\
\text { terial }\end{array}$ & $\begin{array}{c}\text { jar } \\
\text { size } \\
(\mathrm{mL})\end{array}$ & $\begin{array}{c}\text { number of } \\
\text { balls } \\
(\text { mass, } \mathrm{g})\end{array}$ & $\begin{array}{c}\text { ball } \\
\text { size } \\
(\mathrm{mm})\end{array}$ & $\begin{array}{c}\text { NMR } \\
\text { yield } \\
(\%)\end{array}$ \\
\hline 1 & $\begin{array}{c}\text { stainless } \\
\text { steel }\end{array}$ & 1.5 & 1 & 5 & 72 \\
& & & $(0.5 \mathrm{~g} \times 1)$ & &
\end{tabular}

(SUS420J2)

\begin{tabular}{|c|c|c|c|c|c|}
\hline 2 & $\begin{array}{c}\text { stainless } \\
\text { steel } \\
\text { (SUS420J2) }\end{array}$ & 5.0 & $\begin{array}{c}1 \\
(4.0 \mathrm{~g} \times 1)\end{array}$ & 10 & 51 \\
\hline 3 & Agate & 5.0 & $\begin{array}{c}1(1.4 \mathrm{~g} \times \\
1)\end{array}$ & 10 & 16 \\
\hline 4 & $\mathrm{ZrO}_{2}$ & 10 & $\begin{array}{c}2(3.0 \times 2 \\
\text { g) }\end{array}$ & 10 & 5 \\
\hline 5 & $\begin{array}{c}\text { stainless } \\
\text { steel } \\
\text { (SUS420J2) }\end{array}$ & 5.0 & $\begin{array}{c}2(4.0 \times 2 \\
g)\end{array}$ & 10 & 82 \\
\hline 6 & $\begin{array}{c}\text { stainless } \\
\text { steel } \\
\text { (SUS420J2) }\end{array}$ & 5.0 & $\begin{array}{c}3(4.0 \times 3 \\
\text { g) }\end{array}$ & 10 & $>99$ \\
\hline $7^{b}$ & $\begin{array}{c}\text { stainless } \\
\text { steel } \\
\text { (SUS420J2) }\end{array}$ & 5.0 & $\begin{array}{c}3(4.0 \times 3 \\
\mathrm{g})\end{array}$ & 10 & 67 \\
\hline
\end{tabular}

With the optimized conditions in hand, we explored the scope and limitations of aryl bromides in the present solid-state $\mathrm{C}-\mathrm{N}$ cross-coupling reaction system in air (Table 3). This reaction is applicable to a wide range of substrates and permits the synthesis of various triarylamines that contain large polycyclic hydrocarbon cores. For example, naphthalene, pyrene, triphenylene, fluorene, acenaphthene, phenanthrene, and anthracene efficiently formed the corresponding triarylamines (3a-3i) in moderate to high yields. Unfortunately, the present catalytic system is very sensitive to steric hinderance in the aryl halides, i.e., substrates such as 1-bromonaphthalene derivatives (1g and $\mathbf{1 h}$ ) and 9-boromoanthracene (1i) provided the corresponding coupling products (3g-3i) in low yield (12-37\%). Triarylamines that contain internal alkyne (3j) and stilbene (3k) moieties were synthesized in good yield (84\% and $80 \%$, respectively) under the optimized conditions. Unfortunately, the reaction between 2chloronaphthalene (1-b') and diphenylamine (2a) afforded the product ( $\mathbf{3 b}$ ) in very low yield ( $8 \%$ ).

Next, we explored various amine nucleophiles (Table 3). Both bis(4-methylphenyl)amine (2b) and bis(4-methoxyphenyl)amine (2c) were reacted with 1c under the optimized conditions to form the desired products (3l and $\mathbf{3 m}$ ) in high yield (87\% and 93\%, respectively). Diarylamines that contain a naphthyl group (2d and $\mathbf{2 e}$ ) are also compatible under the applied conditions (64\% and 60\% yield, respectively). Finally, this method was applied to boron-substituted or ketone-containing substrates to form the corresponding functionalized triarylamines ( $\mathbf{3 p}$ and $\mathbf{3 q}$ ) in $42 \%$ and $96 \%$ yield, respectively.

\section{Table 3. Substrate Scope. ${ }^{a}$}



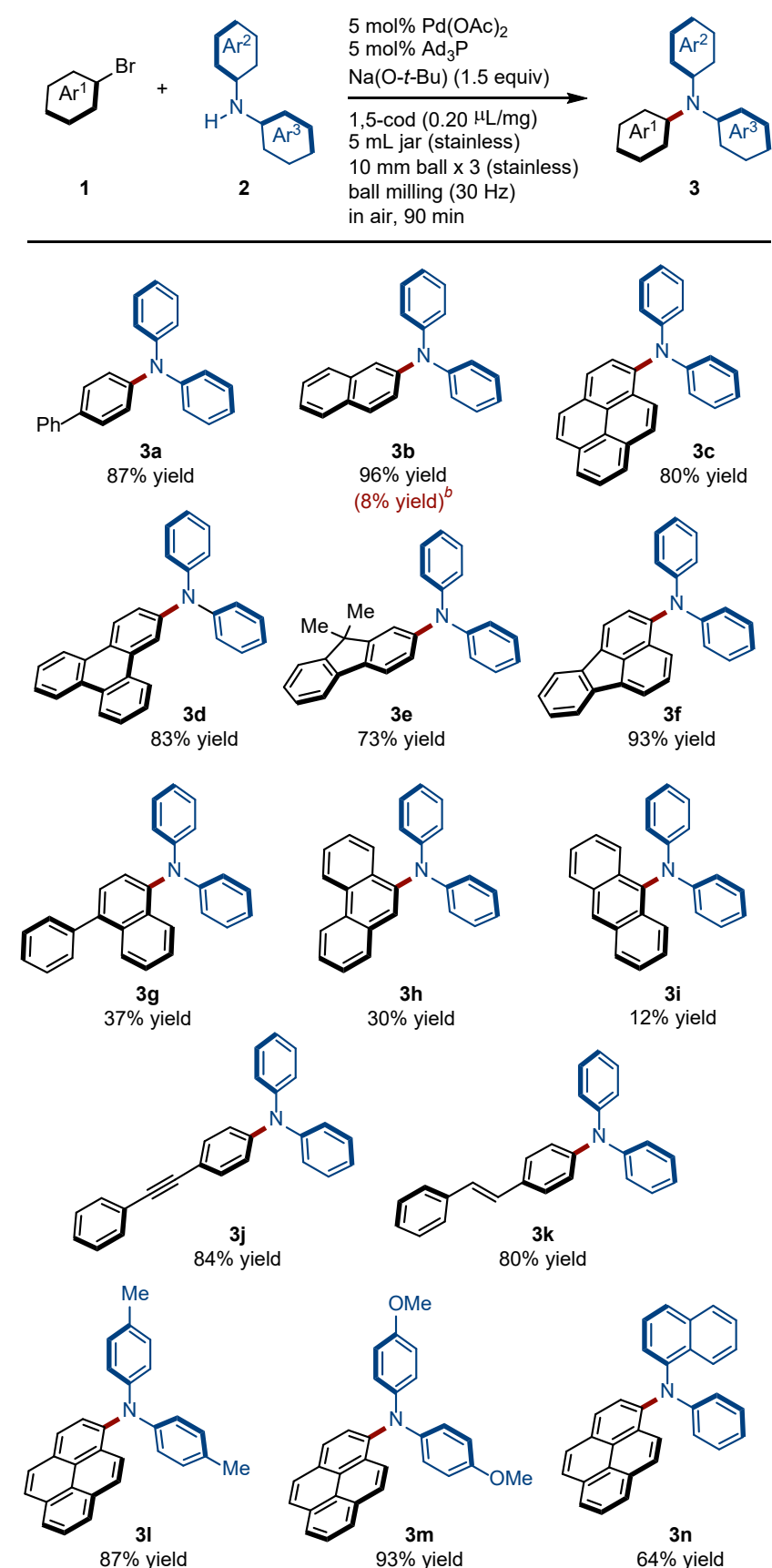

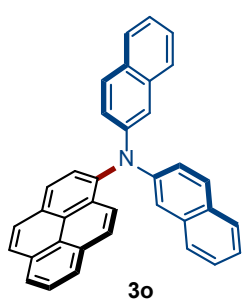

$60 \%$ yield

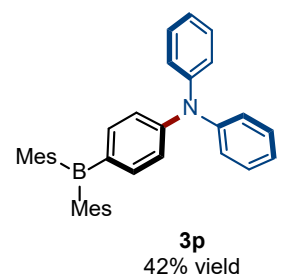

$3 p$
$42 \%$ yield

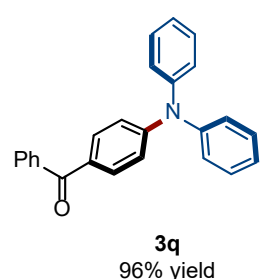

$96 \%$ yield
${ }^{a}$ Conditions: $1(0.50 \mathrm{mmol}), 2(0.50 \mathrm{mmol}), \mathrm{Pd}(\mathrm{OAc})_{2}$ $(0.025 \mathrm{mmol}), \mathrm{Ad}_{3} \mathrm{P}(0.025 \mathrm{mmol}), \mathrm{Na}(\mathrm{O}-t-\mathrm{Bu})(0.75$ $\mathrm{mmol})$, and $1,5-\operatorname{cod}(0.20 \mu \mathrm{L} / \mathrm{mg})$ in a stainless-steel ballmilling jar (5 mL) with three stainless-steel balls (10 $\mathrm{mm}$ ). ${ }^{b 2}$-Chloronaphthalene (1 $\mathbf{b}^{\prime}$ ) was used instead of $\mathbf{1 b}$.

To demonstrate the practical utility of this protocol, we investigated the gram-scale synthesis of triarylamines under mechanochemical conditions in air (Scheme 2). The reaction of $1 \mathbf{b}$ with $2 \mathbf{a}$ was conducted on a $4.5 \mathrm{mmol}$ scale under the modified mechanochemical conditions using a stainless-steel ball milling jar $(10 \mathrm{~mL})$ with three stainless-steel balls (diameter: $10 \mathrm{~mm}$ ). Pleasingly, the gramscale reaction proceeded smoothly, providing $\mathbf{3 b}$ in $80 \%$ yield. This result demonstrates the potential utility of the present mechanochemical protocol for the large-scale preparation of valuable synthetic targets in air.

Scheme 2. Gram-scale Synthesis.

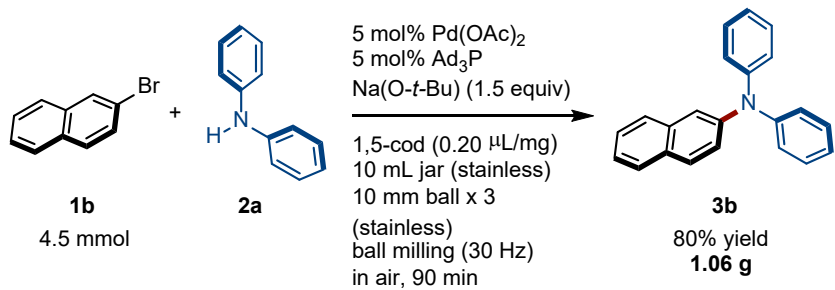

To demonstrate the applicability of the developed mechanochemical conditions to the synthesis of triarylamine-based organic materials, we synthesized hole-transporting materials for organic light-emitting diodes (Scheme 3). ${ }^{42-44,52,53}$ Under the optimized conditions, the reaction of 4,4'-dibromo-1,1'-biphenyl (10) and $\mathbf{2 d}$ afforded the targeted triarylamine $(3 \mathbf{r}$ ) in excellent yield (96\%). ${ }^{52,53}$ This result suggests outstanding potential of this solid-state $\mathrm{C}-\mathrm{N}$ coupling reaction for the efficient preparation of materials-science-oriented nitrogen-containing polyaromatic compounds in an environmentally friendly manner.

Scheme 3. Mechanochemical Synthesis of a Holetransporting Material.
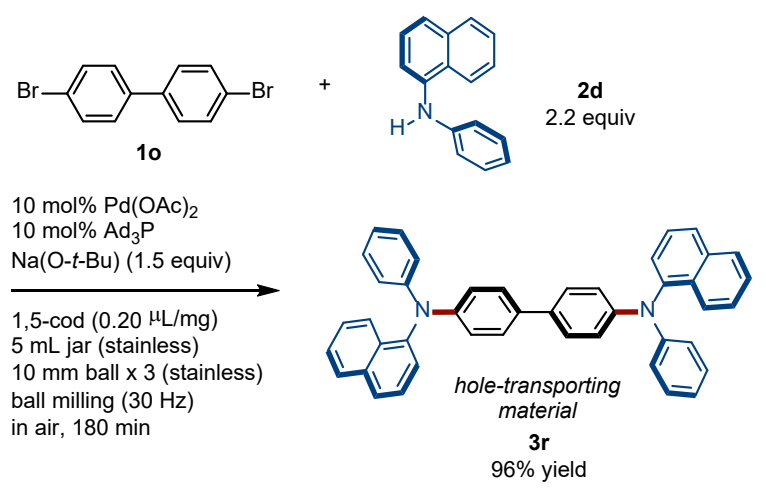

To determine the mechanism by which increasing the number of balls facilitates the solid-state $\mathrm{Pd}(\mathrm{OAc})_{2} / \mathrm{Ad}_{3} \mathrm{P}-$ catalyzed $\mathrm{C}-\mathrm{N}$ coupling reaction, we conducted preliminary mechanistic studies (Figure 1). First, in order to investigate whether the acceleration effect originates the frictional heat during ball milling, the temperature inside the milling jar during the mechanochemical coupling reaction of $1 \mathbf{a}$ and 2a was measured using thermography immediately after opening the jar (Figure 1A). The thermography images showed that the temperature after the coupling reactions under the optimized conditions using different numbers of 10 -mm balls was $\sim 40{ }^{\circ} \mathrm{C}\left(< \pm 3{ }^{\circ} \mathrm{C}\right)$ in all cases, which discounts the possibility of a thermally induced acceleration due to heat generated by the ball milling.

Subsequently, we measured the kinetics of reactions with different numbers of balls (Figure S2-S4). As periodic sampling of the reaction runs requires stopping the mill 
and opening the jar, each data point was obtained from an individual reaction. The reaction using three balls (diameter: $10 \mathrm{~mm}$ ) did not proceed during the first $30 \mathrm{~min}$ but was subsequently rapidly completed within $90 \mathrm{~min}$ (Figure S2). Unfortunately, the reactions using one or two balls were not reproducible, impeding a kinetic analysis (Figure S3 and S4). At this point, we think that this irreproducibility is due to the poor mixing efficiency of the solid-state reaction mixture under these conditions. To test this hypothesis, the surface morphology of the milled 2a was analyzed using scanning electron microscopy (SEM) (Figure 1B). The SEM image of commercially available 2 a shows fine particles with a diameter range of $<500$ $\mu \mathrm{m}$ [Figure $1 \mathrm{~B}(\mathrm{a})]$. The distortion of the particles became more pronounced with increasing number of balls under the applied mechanochemical conditions [Figure $1 B(b)-1 B(d)]$. This result implies that increasing the number of balls increases the surface area of the reactant by crushing it into finer particles, thus facilitating the solidstate coupling reactions and providing good reproducibility.

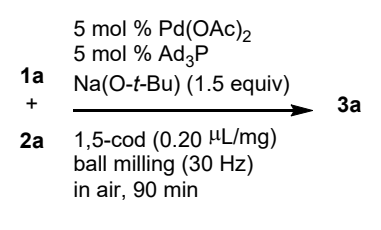

A Thermographic images of the milling jar after the reactions
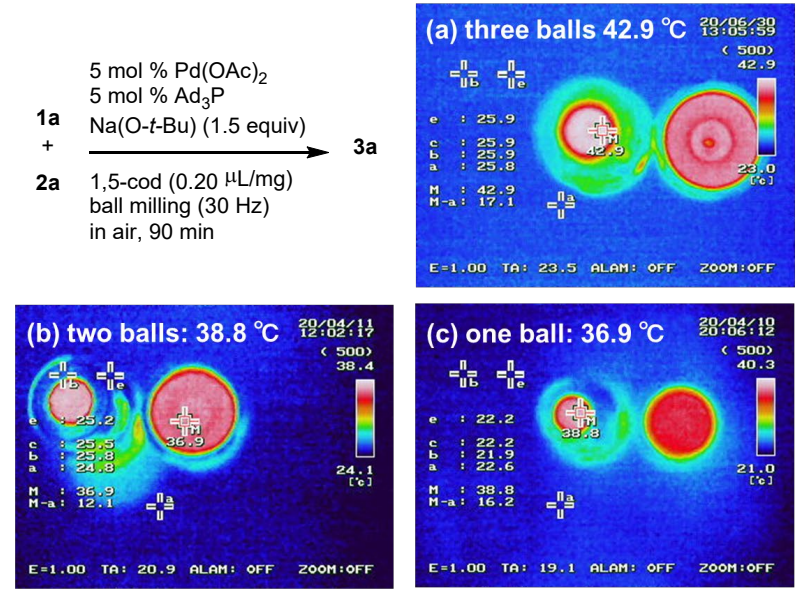

B SEM images of $\mathbf{2} \mathbf{a}$ before and after ball milling
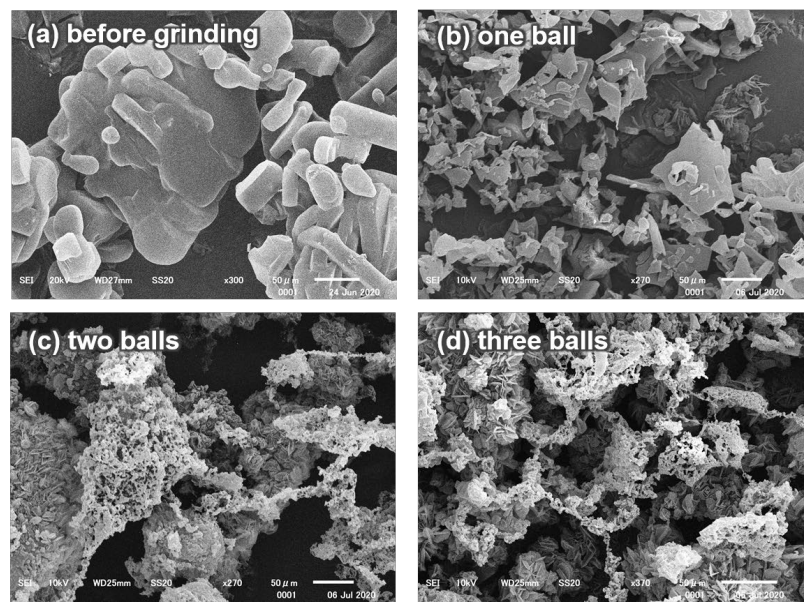

Figure 1. Mechanistic Studies. (A) Thermographic images of the milling jar after the solid-state cross-coupling reactions between $\mathbf{1 a}$ and $\mathbf{2 a}$ under the optimized conditions. (B) SEM images of 2a (a) before ball milling and after ball milling (30 Hz) using (b) one ball, (c) two balls, (d) or three balls (ball diameter: $10 \mathrm{~mm}$ ) for $60 \mathrm{~min}$. Scale bars in the SEM images (bottom left): $50 \mu \mathrm{m}$.
In summary, we have developed a glove-box-andSchlenk-line-free protocol for the solid-state C-N crosscoupling reactions catalyzed by the $\mathrm{Pd}(\mathrm{OAc})_{2} / \mathrm{Ad}_{3} \mathrm{P}$ system. The present mechanochemical cross-coupling reactions can be conducted in the solid-state in air and does not require glove-box and Schlenk-line techniques. The present approach would therefore provide a practical and sustainable method to complement conventional solutionbased palladium-catalyzed $\mathrm{C}-\mathrm{N}$ bond-forming reactions for the synthesis of valuable triarylamine-based materials.

\section{ASSOCIATED CONTENT}

\section{Supporting Information}

Experimental procedures and characterization of new compounds are provided in the Supporting Information. This material is available free of charge via the Internet at http://pubs.acs.org.

\section{AUTHOR INFORMATION}

\section{Corresponding Author \\ *Email: kbt@eng.hokudai.ac.jp \\ *Email: hajito@eng.hokudai.ac.jp}

\section{Notes}

The authors declare no competing financial interest.

\section{ACKNOWLEDGMENT}

This work was financially supported by the Japan Society for the Promotion of Science (JSPS) via KAKENHI grants 18H03907, 17H06370, 19K15547, and 20H04795; by JST CREST grant JPMJCR19R1, and by the Institute for Chemical Reaction Design and Discovery (ICReDD), which has been established by the World Premier International Research Initiative (WPI), MEXT, Japan. We would also like to thank Nippon Chemical Industrial Co., Ltd. for the generous donation of Buchwald ligands.

\section{REFERENCES}

(1) Ruiz-Castillo, P.; Buchwald, S. L. Applications of PalladiumCatalyzed C-N Cross-Coupling Reactions. Chem. Rev. 2016, 116, 12564-12649. DOI: 10.1021/acs.chemrev.6b00512.

(2) Magano, J.; Dunetz, J. R. Large-Scale Applications of Transition Metal-Catalyzed Couplings for the Synthesis of Pharmaceuticals. Chem. Rev. 2011, 111, 2177-2250. DOI: 10.1021/cr100346g.

(3) Beletskaya, I. P.; Cheprakov, A. V. The Complementary Competitors: Palladium and Copper in $\mathrm{C}-\mathrm{N}$ Cross-Coupling Reactions. Organometallics 2012, 31, 7753-7808. DOI: 10.1021/om300683c.

(4) Schlummer, B.; Scholz, U. Palladium-Catalyzed C-N and C-O Coupling Cross-Coupling - A Practical Guide from an Industrial Vantage Point. Adv. Synth. Catal. 2004, 346, 1599-1626. DOI: 10.1002/adsc.200404216.

(5) Surry, D. S.; Buchwald, S. L. Biaryl Phosphane Ligands in Palladium-Catalyzed Amination. Angew. Chem., Int. Ed. 2008, 47, 6338-6361. DOI: 10.1002/anie.200800497.

(6) Wolfe, J. P.; Wagaw, S.; Marcoux, J.-F.; Buchwald, S. L. Rational Development of Practical Catalysts for Aromatic CarbonNitrogen Bond Formation. Acc. Chem. Res. 1998, 31, 805-818. DOI: $10.1021 /$ ar9600650.

(7) Surry, D. S.; Buchwald, S. L. Dialkylbiaryl Phosphines in PdCatalyzed Amination: A User's Guide. Chem. Sci. 2011, 2, 27-50. DOI: $10.1039 /$ CoSC00331J. 
(8) Hartwig, J. F. Evolution of a Fourth Generation Catalysts for the Amination and Thioetherification of Aryl Halides. Acc. Chem. Res. 2008, 41, 1534-1544. DOI: 10.1021/ar800098p.

(9) Federsel, H.-J.; Hedberg, M.; Qvarnström, F. R.; Tian, W. Optimization and Scale-Up of a Pd-Catalyzed Aromatic C-N Bond Formation: A Key Step in the Synthesis of a Novel 5- $\mathrm{HT}_{1 \mathrm{~B}}$ Receptor Antagonist. Org. Process Res. Dev. 2008, 12, 512-521. DOI: 10.1021/op8000146.

(10) Lan, X.-B.; Li, Y.; Li, Y.-F.; Shen, D.-S.; Ke, Z.; Liu, F.-S. Flexible Steric Bulky Bis(Imino)acenaphthene (BIAN)-Supported N-Heterocyclic Carbene Palladium Precatalysts: Catalytic Application in Buchwald-Hartwig amination in Air. J. Org. Chem. 2017, 82, 2914-2925. DOI: 10.1021/acs.joc.6b02867.

(11) Huang, F.-D.; Xu, C.; Lu, D.-D.; Shen, D.-S.; Li, T.; Liu, F.-S. PdPEPPSI-IPent ${ }^{A n}$ Promoted Deactivated Amination of Aryl Chlorides with Amines under Aerobic Conditions. J. Org. Chem. 2018, 83, 9144-9155. DOI: 10.1021/acs.joc.8b01205.

(12) James, S. L.; Adams, C. J.; Bolm, C.; Braga, D.; Collier, P.; Friščić, T.; Grepioni, F.; Harris, K. D. M.; Hyett, G.; Jones, W.; Krebs, A.; Mack, J.; Maini, L.; Orpen, A. G.; Parkin, I. P.; Shearouse, W. C.; Steed, J. W.; Waddell, D. C. Mechanochemistry: Opportunities for New and Cleaner Synthesis. Chem. Soc. Rev. 2012, 41, 413-447. DOI: $10.1039 / \mathrm{C} 1 \mathrm{CS} 15171 \mathrm{~A}$.

(13) Wang, G.-W. Mechanochemical Organic Synthesis. Chem. Soc. Rev. 2013, 42, 7668-7700. DOI: 10.1039/C3CS35526H.

(14) Do, J.-L.; Friščić, T. Mechanochemistry: A Force of Synthesis. ACS Cent. Sci. 2017, 3, 13-19. DOI: 10.1021/acscentsci.6b00277.

(15) Hernández, J. G.; Bolm, C. Altering Product Selectivity by Mechanochemistry. J. Org. Chem. 2017, 82, 4007-4019. DOI: 10.1021/acs.joc.6b02887.

(16) Métro, T.-X.; Martinez, J.; Lamaty, F. 1,1'-Carbonyldiimidazole and Mechanochemistry: A Shining Green Combination. ACS Sustainable Chem. Eng. 2017, 5, 9599-9602. DOI: 10.1021/acssuschemeng.7b03260.

(17) Achar, T. K.; Bose, A.; Mal, P. Mechanochemical Synthesis of Small Organic Molecules. Beilstein J. Org. Chem. 2017, 13, 1907-1931. DOI: 10.3762/bjoc.13.186.

(18) Eguaogie, O.; Vyle, J. S.; Conlon, P. F.; Gîlea, M. A.; Liang, Y. Mechanochemistry of Nucleosides, Nucleotides and Related Materials. Beilstein J. Org. Chem. 2018, 14, 955-970. DOI: 10.3762/bjoc.14.81.

(19) Howard, J. L.; Cao, Q.; Browne, D. L. Mechanochemistry as an Emerging Tool for Molecular Synthesis: What Can It Offer? Chem. Sci. 2018, 9, 3080-3094. DOI: 10.1039/C7SC05371A.

(20) Andersen, J.; Mack, J. Mechanochemistry and Organic Synthesis: From Mystical to Practical. Green Chem. 2018, 20, 1435-1443. DOI: 10.1039/C7GC03797J.

(21) Bolm, C.; Hernández, J. G. Mechanochemistry of Gaseous Reactants. Angew. Chem., Int. Ed. 2019, 58, 3285-3299. DOI: 10.1002/anie.201810902.

(22) Friščić, T.; Mottillo, C.; Titi, H. M. Mechanochemistry for Synthesis. Angew. Chem., Int. Ed. 2020, 59, 1018-1029. DOI: 10.1002/anie.201906755.

(23) Porcheddu, A.; Colacino, E.; Luca, L. D.; Delogu, F. Metal-Mediated and Metal-Catalyzed Reactions Under Mechanochemical Conditions. ACS Catal. 2020, 10, 8344-8394. DOI: 10.1021/acscatal.0c00142.

(24) Pérez-Venegas, M.; Juaristi, E. Mechanochemical and Mechanoenzymatic Synthesis of Pharmacologically Active Compounds: A Green Perspective. ACS Sustainable Chem. Eng. 2020, 8, 8881-8893. DOI: 10.1021/acssuschemeng.0c01645.

(25) Kubota, K.; Pang, Y.; Miura, A.; Ito, H. Redox Reactions of Small Organic Molecules Using Ball Milling and Piezoelectric Materials. Science 2019, 366, 1500-1504. DOI: 10.1126/science.aay8224.

(26) Pang, Y.; Ishiyama, T.; Kubota, K.; Ito, H. Iridium(I)-Catalyzed C-H Borylation in Air by Using Mechanochemistry. Chem. Eur. J. 2019, 25, 4654-4659. DOI: 10.1002/chem.201900685.

(27) Kubota, K.; Takahashi, R.; Ito, H. Mechanochemistry Allows Carrying Out Sensitive Organometallic Reagents in Air: Glove-
Box-and-Schlenk-Line-Free Synthesis of Oxidative Addition Complexes from Aryl Halides and Palladium(0). Chem. Sci. 2019, 10, 5837-5842. DOI: 10.1039/C9SC01711A

(28) Seo, T.; Ishiyama, T.; Kubota, K.; Ito, H. Solid-State SuzukiMiyaura Cross-Coupling Reactions: Olefin-Accelerated C-C Coupling Using Mechanochemistry. Chem. Sci. 2019, 10, 8202-8210. DOI: $10.1039 / C 9 S C 02185$ J.

(29) Takahashi, R.; Kubota, K.; Ito, H. Air- and Moisture-Stable Xantphos-Ligated Palladium Dialkyl Complex as a Precatalyst for Cross-Coupling Reactions. Chem. Commun. 2020, 56, 407-410. DOI: 10.1039/C9CC06946A.

(30) Seo, T.; Kubota, K.; Ito, H. Selective Mechanochemical Monoarylation of Unbiased Dibromoarenes by in Situ Crystallization. J. Am. Chem. Soc. 2020, 142, 9884-9889. DOI: 10.1021/jacs.0c01739.

(31) Shao, Q.-L.; Jiang, Z.-J.; Su, W.-K. Solvent-Free Mechanochemical Buchwald-Hartwig Amination of Aryl Chlorides without Inert Gas Protection. Tetrahedron Lett. 2018, 59, 2277-2280. DOI: $10.1016 /$ j.tetlet.2018.04.078.

(32) Cao, Q.; Nicholson, W. I.; Jones, A. C.; Browne, D. L. Robust Buchwald-Hartwig Amination Enabled by Ball-Milling. Org. Biomol. Chem. 2019, 17, 1722-1726. DOI: 10.1039/C80B01781F.

(33) Kubota, K.; Seo, T.; Koide, K.; Hasegawa, Y.; Ito, H. OlefinAccelerated Solid-State C-N Cross-Coupling Reactions Using Mechanochemistry. Nat. Commun. 2019, 10, 111-122. DOI: 10.1038/s41467-018-08017-9.

(34) Nielsen, S. F.; Peters, D.; Axelsson, O. The Suzuki Reaction under Solvent-Free Conditions. Synth. Commun. 2000, 30, 3501-3509. DOI: 10.1080/00397910008087262.

(35) Schneider, F.; Stolle, A.; Ondruschka, B.; Hopf, H. The Suzuki-Miyaura Reaction under Mechanochemical Conditions. Org. Process Res. Dev. 2009, 13, 44-48. DOI: 10.1021/op800148y.

(36) Jiang, Z.-J.; Li, Z.-H.; Yu, J.-B.; Su, W.-K. Liquid-Assisted Grinding Accelerating: Suzuki-Miyaura Reaction of Aryl Chlorides under High-Speed Ball-Milling Conditions. J. Org. Chem. 2016, 81, 10049-10055. DOI: 10.1021/acs.joc.6b01938.

(37) Tullberg, E.; Peters, D.; Frejd, T. The Heck Reaction under Ball-Milling Conditions. J. Organomet. Chem. 2004, 689, 3778-3781. DOI: 10.1016/j.jorganchem.2004.06.045.

(38) Declerck, V.; Colacino, E.; Bantreil, X.; Martinez, J.; Lamaty, F. Poly(ethylene glycol) as Reaction Medium for Mild Mizoroki-Heck Reaction in a Ball-Mill. Chem. Commun. 2012, 48, 11778-11780. DOI: 10.1039/C2CC36286D.

(39) Fulmer, D. A.; Shearouse, W. C.; Medonza, S. T.; Mack, J. Solvent-Free Sonogashira Coupling Reaction via High Speed Ball Milling. Green Chem. 2009, 11, 1821-1825. DOI: 10.1039/B915669K.

(40) Cao, Q.; Howard, J. L.; Wheatley, E.; Browne, D. L. Mechanochemical Activation of Zinc and Application to Negishi Cross-Coupling. Angew. Chem., Int. Ed. 2018, 130, 11339-11343. DOI: 10.1002/anie.201806480.

(41) Lou, S.-J.; Mao, Y.-J.; Xu, D.-Q.; He, J.-Q.; Chen, Q.; Xu, Z.-Y. Fast and Selective Dehydrogenative $\mathrm{C}-\mathrm{H} / \mathrm{C}-\mathrm{H}$ Arylation Using Mechanochemistry. ACS Catal. 2016, 6, 3890-3894. DOI: 10.1021/acscatal.6b00861.

(42) Ning, Z.; Tian, H. Triarylamine: A Promising Core Unit for Efficient Photovoltaic Materials. Chem. Commun. 2009, 5483-5495. DOI: 10.1039/B908802D.

(43) Li, L.-L.; Diau, E. W.-G. Porphyrin-Sensitized Solar Cells. Chem. Soc. Rev. 2013, 42, 291-304. DOI: 10.1039/C2CS35257E.

(44) Jeon, N. J.; Lee, J.; Noh, J. H.; Nazeeruddin, M. K.; Grätzel, M.; Seok, S. I. Efficient Inorganic-Organic Hydride Perovskite Solar Cells Based on Pyrene Arylamine Derivatives as Hole-Transporting Materials. J. Am. Chem. Soc. 2013, 135, 19087-19090. DOI: 10.1021/ja410659k.

(45) Hartwig, J. F.; Kawatsura, M.; Hauck, S. I.; Shaughnessy, K. H.; Alcazar-Roman L. M. Room-Temperature Palladium-Catalyzed Amination of Aryl Bromides and Chlorides and Extended 
Scope of Aromatic C-N Bond Formation with a Commercial Ligand. J. Org. Chem. 1999, 64, 5575-5580. DOI: 10.1021/jo990408i.

(46) Chen, L.; Ren, P.; Carrow, B. P. Tri(1-adamantyl)phosphine: Expanding the Boundary of Electron-Releasing Character Available to Organophosphorus Compounds. J. Am. Chem. Soc. 2016, 138, 6392-6395. DOI: 10.1021/jacs.6b03215.

(47) Carrow, B. P.; Chen, L. Tri(1-adamantyl)phosphine: Exceptional Catalytic Effects Enabled by the Synergy of Chemical Stability, Donicity, and Polarizability. Synlett 2017, 28, 280-288. DOI: $10.1055 / \mathrm{s}-0036-1588128$.

(48) Chen, L.; Sanchez, D. R.; Zhang, B.; Carrow, B. P. 'Cationic' Suzuki-Miyaura Coupling with Acutely Base-Sensitive Boronic Acids. J. Am. Chem. Soc. 2017, 139, 12418-12421. DOI: 10.1021/jacs.7b07687.

(49) Chen, L.; Francis, H.; Carrow, B. P. An 'On-Cycle’ Precatalyst Enables Room Temperature Polyfluoroarylation Using Sensitive Boronic Acids. ACS Catal. 2018, 4, 2989-2994. DOI: 10.1021/acscatal.8b00341.

(50) Dong, J.; Guo, H.; Hu, Q.-S. Controlled Pd(0)/Ad 3 P-Catalyzed Suzuki Cross-Coupling Polymerization of AB-type Monomers with $\mathrm{Ad}_{3} \mathrm{P}$-Coordinated Acetanilide-Based Palladacycle Complex as Initiator. ACS Macro Lett. 2017, 6, 1301-1304. DOI: 10.1021/acsmacrolett.7b00759.

(51) Given that the mechanochemical conditions used by Su and Browne are different from those used in this study, it is not possible to conclude that the performance of their catalytic systems is inferior/superior/equal to that of our catalytic system.

(52) Luo, D.; Yang, Y.; Xiao, Y.; Zhao, Y.; Yang, Y.; Liu, B. Regulating Charge and Exciton distribution in High-Performance Hybrid White Organic Light-Emitting Diodes with n-Type Interlayer Switch. Nano-Micro Lett. 2017, 9, 37. DOI: 10.1007/s40820-0170138-4.

(53) Yoo, S.-J.; Chang, J.-H.; Lee, J.-H.; Moon, C.-K.; Wu, C.-I.; Kim, J.-J. Formation of Perfect Ohmic Contact at Indium Tin Oxide/ $N, N^{\prime}$-di(naphthalene-1-yl)- $N, N^{\prime}$-diphenyl-Benzidine Interface Using $\mathrm{ReO}_{3}$. Sci. Rep. 2015, 4, 3092. DOI: 10.1038/srep03902. 


\section{TOC figure:}

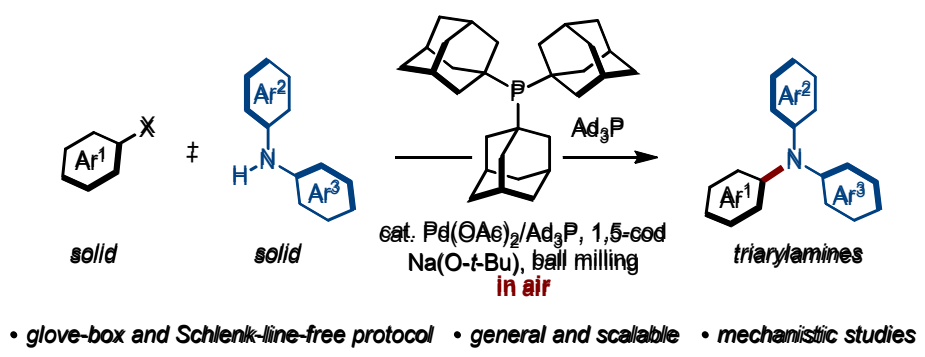

Synopsis: The development of operationally simple mechanochemical solid-state C-N cross-coupling reactions in air is reported. 